\title{
Multifunctional Integrated Transparent Film for Efficient Electromagnetic Protection
}

Cite as

Nano-Micro Lett.

(2022) 14:65

\author{
Gehuan Wang ${ }^{1}$, Yue Zhao ${ }^{1}$, Feng Yang ${ }^{1}$, Yi Zhang ${ }^{1}$, Ming Zhou ${ }^{1}$, Guangbin $\mathrm{Ji}^{1}{ }^{凶}$
}

Received: 16 December 2021

Accepted: 18 January 2022

Published online: 23 February 2022

(C) The Author(s) 2022

\section{HIGHLIGHTS}

- The reduced graphene oxide (rGO) decorated silver nanowire (Ag NW) films were prepared by spray-coating method.

- A highly efficient conductive network was constructed by $\mathrm{Ag} \mathrm{NW}$ and rGO, achieving superior electromagnetic interference shielding effectiveness of $33.62 \mathrm{~dB}$ with a high transmittance of $81.9 \%$.

- The top rGO layer enables the hybrid film with reliable durability, chemical and thermal stabilities.

ABSTRACT Silver nanowire (Ag NW) has been considered as the promising building block for the fabrication of transparent electromagnetic interference (EMI) shielding films. However, the practical application of Ag NW-based EMI shielding films has been restricted due to the unsatisfactory stability of Ag NW. Herein, we proposed a reduced graphene oxide (rGO) decorated Ag NW film, which realizes a seamless integration of optical transparency, highly efficient EMI shielding, reliable durability and stability. The Ag NW constructs a highly transparent and conductive network, and the rGO provides additional conductive path, showing a superior EMI shielding effectiveness (SE) of $33.62 \mathrm{~dB}$ at transmittance of $81.9 \%$. In addition, the top rGO layer enables the hybrid film with reliable durability and chemical stability, which can maintain $96 \%$ and $90 \%$ EMI $\mathrm{SE}$ after 1000 times bending cycles at radius of $2 \mathrm{~mm}$ and exposure in air for 80 days. Furthermore, the rGO/Ag NW films also possess fast thermal

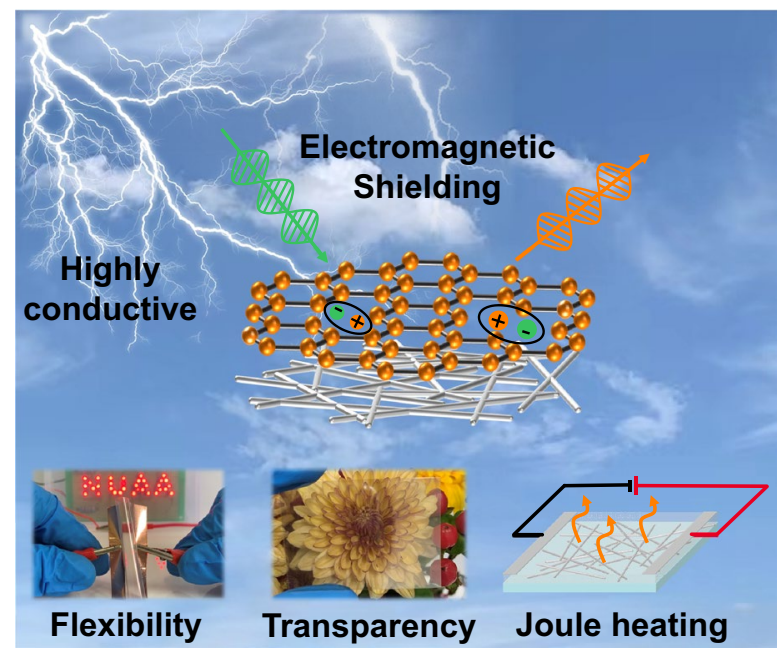
response and heating stability, making them highly applicable in wearable devices. The synergy of Ag NW and rGO grants the hybrid EMI shielding film multiple desired functions and meanwhile overcomes the shortcomings of $\mathrm{Ag}$ NW. This work provides a reference for preparing multifunctional integrated transparent EMI shielding film.

KEYWORDS Reduced graphene oxide; Electromagnetic interference shielding; Flexible; Transparent; Silver nanowire

Guangbin Ji,gbji@nuaa.edu.cn

${ }^{1}$ College of Materials Science and Technology, Nanjing University of Aeronautics and Astronautics, Nanjing 210016, People's Republic of China 


\section{Introduction}

Entering into the age of fifth generation communication, the mushroom development of wireless communication equipment and flexible electronics has accelerated the human society process. However, the accompanying electromagnetic radiation becomes a "health killer" to human [1-4]. Exploring materials with high-efficient and stable electromagnetic wave attenuation capability is a feasible strategy to reduce electromagnetic pollution [5, 6]. Recently, transparent EMI shielding films have sparked huge interest of researchers because these films can meet the requirements of optical observation and electromagnetic protection at the same time [7, 8]. Indium tin oxide (ITO) has been widely used due to its high optical transmittance and good electrical conductivity. However, the inherent brittleness limits its employment in flexible electronics $[9,10]$. Ag NW enters the vision of researchers due to excellent electrical conductivity and mechanical flexibility. Moreover, the opening spaces of Ag NW percolation network allow visible light transmission, showing high optical transmittance [11]. For instance, Jung et al. proposed a transparent and stretchable Ag NW-based EMI shielding film, which was prepared by deposing Ag NW network on elastic poly(dimethylsiloxane) (PDMS) substrate. The transmittance of the Ag NW/PDMS film reaches $76.8 \%$, and shielding effectiveness (SE) of that is $42.5 \mathrm{~dB}$ [12]. Wang et al. prepared a transparent $\mathrm{Fe}_{3} \mathrm{O}_{4}$ modified $\mathrm{Ag}$ NW EMI shielding film through spin coating method, which exhibits a satisfactory SE of $24.9 \mathrm{~dB}$ with high transmittance of $90 \%$ [13].

Although high-quality transparent EMI shielding films can be obtained by using Ag NW as building block, there are still some challenges need to be overcome: (i) Ag NW is susceptible to corrosion in air, resulting in EMI shielding performance degradation; (ii) The weak connection between Ag NWs and substrate makes it easy slide and break during bending process; (iii) The insulating capping agent polyvinyl pyrrolidone (PVP) absorbed on the surface of Ag NW and loose contact of adjacent of Ag NWs results in high contact resistance $[14,15]$. Introducing a two-dimensional building block as the functional layer is a feasible method to solve these issues mentioned above. For example, Zhang's group prepared a transition metal carbide/carbonitride (MXene) decorated Ag NW via spray-coating technology. With the help of solvent evaporation induced capillary force, the adjacent Ag NWs can be welded by MXene nanosheets, thus significantly reducing the sheeting resistance (Rs), showing SE about $30 \mathrm{~dB}$ with a transmittance of $83 \%$. Besides, the MXene protect layer endows composite film with stable EMI shielding performance after 70 days aging [16]. Liang et al. reported a graphene oxide (GO) welded Ag NW transparent conductive film with transmittance of $88 \%$ and $\mathrm{R}_{\mathrm{s}}$ of $14 \Omega$ $\mathrm{sq}^{-1}$. After bending 12,000 times with radius of $4 \mathrm{~mm}$, the Rs only increases 2-3\% [17]. It was reported that monolayer graphene prepared by chemical vapor deposition (CVD) method exhibits excellent optical transmittance of $97.8 \%$, while the Rs is up to $635 \Omega \mathrm{sq}^{-1}$ [18]. The combination of CVD-prepared graphene and Ag NW can realize mutually benefit, showing excellent transmittance of $90 \%$ and electrical conductivity of $14 \Omega \mathrm{sq}^{-1}$ [19]. Considering the complicated preparation process of MXene or monolayer graphene, and the poor conductivity of GO, rGO is deemed as the ideal material to improve EMI shielding performance and stability of Ag NW-based films. The chemical reduction in GO film usually uses highly poisonous hydrazine or $\mathrm{NaBH}_{4}[20,21]$. $\mathrm{L}$-ascorbic acid is a nontoxic reducing agent, which reduces GO and does not damage Ag NW network simultaneously.

Herein, we introduce a transparent flexible $\mathrm{rGO} / \mathrm{Ag} \mathrm{NW}$ EMI shielding film, which was fabricated by spray-coating, followed by a mild heating treatment. The rGO nanosheets were uniformly wrapped on the Ag NW network, providing local conductivity for the insulating opening spaces of $\mathrm{Ag}$ NW network. Compared with the original Ag NW film, the EMI shielding properties can be enhanced by rGO decoration, whereas the resultant films remain high optical transmittance. Besides, the resultant film can bear 1000 times bending cycles and keep chemical stability for a long time due to $\mathrm{rGO}$ protection layer. In addition, the rGO endows the $\mathrm{rGO} / \mathrm{Ag} \mathrm{NW}$ film with exceptional thermal repeatability and stability. These charming features grant the $\mathrm{rGO} / \mathrm{Ag}$ NW film promising prospects in wearable and optoelectronic application.

\section{Experimental}

\subsection{Materials}

Ag NW (the diameter and the length are about $30 \mathrm{~nm}$ and $20 \mu \mathrm{m}$, respectively) suspension in ethanol was purchased from Nanjing XFNANO Co., Ltd. GO aqueous solution 
was purchased from Institute of Coal Chemistry Chinese Academy of Sciences. L-ascorbic acid was purchased by Sinopharm Chemical Reagent Co., Ltd. All of the materials can be directly used without purification.

\subsection{Fabrication of rGO/Ag NW Film}

First, the polyethylene terephthalate (PET) substrate was cleaned by absolute alcohol and deionized water for several times and then exposed to UV-ozone atmosphere (SCUV-I) for 5 min. Subsequently, Ag NW network and GO nanosheets were deposited on the PET substrate in turn by a commercial spray gun (S-130). The pressure and distance were $0.3 \mathrm{MPa}$ and $10 \mathrm{~cm}$, respectively. After drying, the $\mathrm{L}$-ascorbic acid solution was poured into an autoclave, the $\mathrm{GO} / \mathrm{Ag} \mathrm{NW}$ film was immersed in it and heated at $95^{\circ} \mathrm{C}$ for $2 \mathrm{~h}$. The mass ratio of GO and L-ascorbic acid was 1:10. Finally, the rGO/Ag NW film was cleaned by deionized water to remove excess L-ascorbic acid, followed by drying. The area density of these building blocks is related to the concentration and volume, which can be expressed by the following equation [22]:

$\sigma_{B}=\frac{C_{B} \times V_{B}}{S_{P E T}}$

where $\sigma_{B}$ represents the area density of building blocks, $C_{B}$ and $V_{B}$ are the concentration and volume of building blocks, and the $\mathrm{S}_{\mathrm{PET}}$ is the area of PET substrate, respectively. The samples were denoted as $\mathrm{rGO} / \mathrm{Ag} \mathrm{NW}$ x/y, where $\mathrm{x}$ and $\mathrm{y}$ represent the area density of rGO and $\mathrm{Ag} \mathrm{NW}$.

\subsection{Characterization}

The micromorphology and elemental composition of the samples were recorded by scanning electron microscope (SEM, Hitachi S4800) and energy-dispersive spectrometer (EDS). The crystal phases of the samples were observed by X-ray diffraction (XRD, Bruker D8 ADVANCE). The binding energy of the samples was recorded by X-ray photoelectron spectrometer (XPS, PHI 5000 VersaProbe). Raman spectra were obtained by Raman spectrometer (Renishaw InVia). The water contact angle was characterized by contact angle meter (SL200B). The transmittance was obtained by UV-visible spectrophotometer (UV-3600). The testing wavelength region ranges from 400 to $800 \mathrm{~nm}$, using neat
PET substrate as the baseline. The sheet resistance was recorded by four-point probe measurement (HPS2661). The electrical heating capability of samples was characterized by a DC power supply source (MS-30100) and the infrared (IR) thermal images was recorded by IR camera (FLIR ONE PRO). The electromagnetic parameters, including reflection $\left(\mathrm{S}_{11}\right)$ and transmission $\left(\mathrm{S}_{12}\right)$ parameters, at $\mathrm{X}$ band (8.2-12.4 GHz) were recorded by vector network analyzer (Agilent PNA N5244A). The EMI shielding performance can be calculated by the electromagnetic parameters, the equations are as follows [23]:

$R=\left|S_{11}\right|^{2}$

$T=\left|S_{12}\right|^{2}$

$A=1-R-T$

$S E_{T}=S E_{R}+S E_{A}$

$S E_{R}=-10 \log (1-R)$

$S E_{A}=-10 \log \left(\frac{T}{1-R}\right)$

where $\mathrm{R}, \mathrm{A}$, and $\mathrm{T}$ represent reflection, absorption, and transmission coefficients, respectively. $\mathrm{SE}_{\mathrm{T}}, \mathrm{SE}_{\mathrm{R}}$, and $\mathrm{SE}_{\mathrm{A}}$ are total, reflection and absorption shielding effectiveness.

\section{Results and Discussion}

\subsection{Fabrication and Characterization of $\mathrm{rGO} / \mathrm{Ag} \mathrm{NW}$ Film}

The schematic fabrication of $\mathrm{rGO} / \mathrm{Ag} \mathrm{NW}$ film is illustrated in Fig. 1a. First, the UV-O 3 atmosphere treatment was used to graft hydrophilic groups on PET substrate, which facilitates the uniform deposition of building blocks. Then, the Ag NW network was first deposited on the substrate, and the GO nanosheets were then uniformly covered on the $\mathrm{Ag}$ NWs surface, forming a sandwich structure. Finally, the GO nanosheets were reduced by L-ascorbic acid under a mild hydrothermal treatment, forming a highly efficient conductive network. As shown in Fig. 1b, Ag NWs were distributed randomly on the PET substrate. The Ag NW/PET film exhibits hydrophilic character with a water contact angle 
of $4.13^{\circ}$, which arises from the hydrophilic capping agent PVP absorbed on the surface of Ag NW. Figure 1c displays the Ag NW network wrapped by GO nanosheets, it also shows hydrophilicity $\left(\theta=31.02^{\circ}\right)$ due to abundant functional groups on the surface of GO. After L-ascorbic acid reduction, the $\mathrm{Ag} \mathrm{NW}$ network maintains integrity. The water contact angle increased significantly $\left(\theta=88.91^{\circ}\right)$, which proved that most functional groups on GO surface have been removed (Fig. 1d). Besides, the EDS spectra proved that $\mathrm{GO}$ and $\mathrm{rGO}$ are coated on the surface of $\mathrm{Ag} \mathrm{NW}$ network successfully (Fig. S1).

For the sake of comparison, we used the same method to prepare rGO nanosheets. As shown in Fig. 2a, the pristine GO exhibits a strong and sharp diffraction peak at $10.2^{\circ}$, corresponding to the (001) plane of GO with interlayer spacing of $8.66 \AA$. After L-ascorbic acid reduction, the peak at $10.2^{\circ}$ disappeared. A broad diffraction peak appears at $23.6^{\circ}$, which is related to the (002) plane of graphite [24, 25]. According to the Bragg's Law, the interlayer spacing of rGO decreases to $3.77 \AA$. The oxygen-containing groups on the GO nanosheets surface have been removed with the help of L-ascorbic acid, resulting in $\pi-\pi$ stacking and graphene aggregation, thus reducing the interlayer spacing of rGO. For the Ag NW network, the XRD pattern shows five typical diffraction peaks centered at $38.1^{\circ}, 44.3^{\circ}, 64.5^{\circ}, 77.4^{\circ}$, and $81.6^{\circ}$, which are indexed to the (111), (200), (220), (311), and (222) crystal plane of face-centered cubic silver, respectively. The XRD pattern of GO/Ag NW shows the typical diffraction peak of $\mathrm{GO}$ and $\mathrm{Ag} \mathrm{NW}$, proving the successful deposition of GO on the Ag NW network. The chemical reducing agent $\mathrm{L}$-ascorbic acid reduced $\mathrm{GO}$ into $\mathrm{rGO}$ without damaging the crystal structure of $\mathrm{Ag}$, which reflected on the disappearance of the characteristic peak of GO at $11.1^{\circ}$ and the existence of characteristic peaks of $\mathrm{Ag} \mathrm{NW}$ at 38.1 and $44.3^{\circ}$ (Fig. 2b).

As shown in Fig. S2a, both GO and rGO exhibit characteristic peaks of carbon materials, which are located at ca. $1350 \mathrm{~cm}^{-1}$ (D band) and ca. $1600 \mathrm{~cm}^{-1}$ (G band). The $\mathrm{D}$ band is related to defective/disorder carbon, and the $\mathrm{G}$ band corresponds to the carbon with $\mathrm{sp}^{2}$-hybrid structure $[26,27]$. The intensity ratio of $\mathrm{D}$ band to $\mathrm{G}$ band $\left(I_{\mathrm{D}} / I_{\mathrm{G}}\right)$ is used to evaluate the defects degree of carbon materials. The $I_{\mathrm{D}} / I_{\mathrm{G}}$ value of GO is 1.07 , and that of rGO increases to 1.48 , which is similar to previous work $\left(I_{\mathrm{D}} / I_{\mathrm{G}}=1.51\right)$ [28]. The

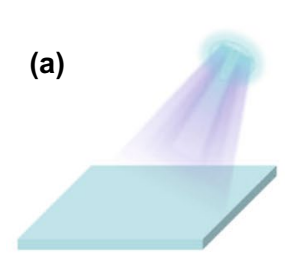

PET substrate
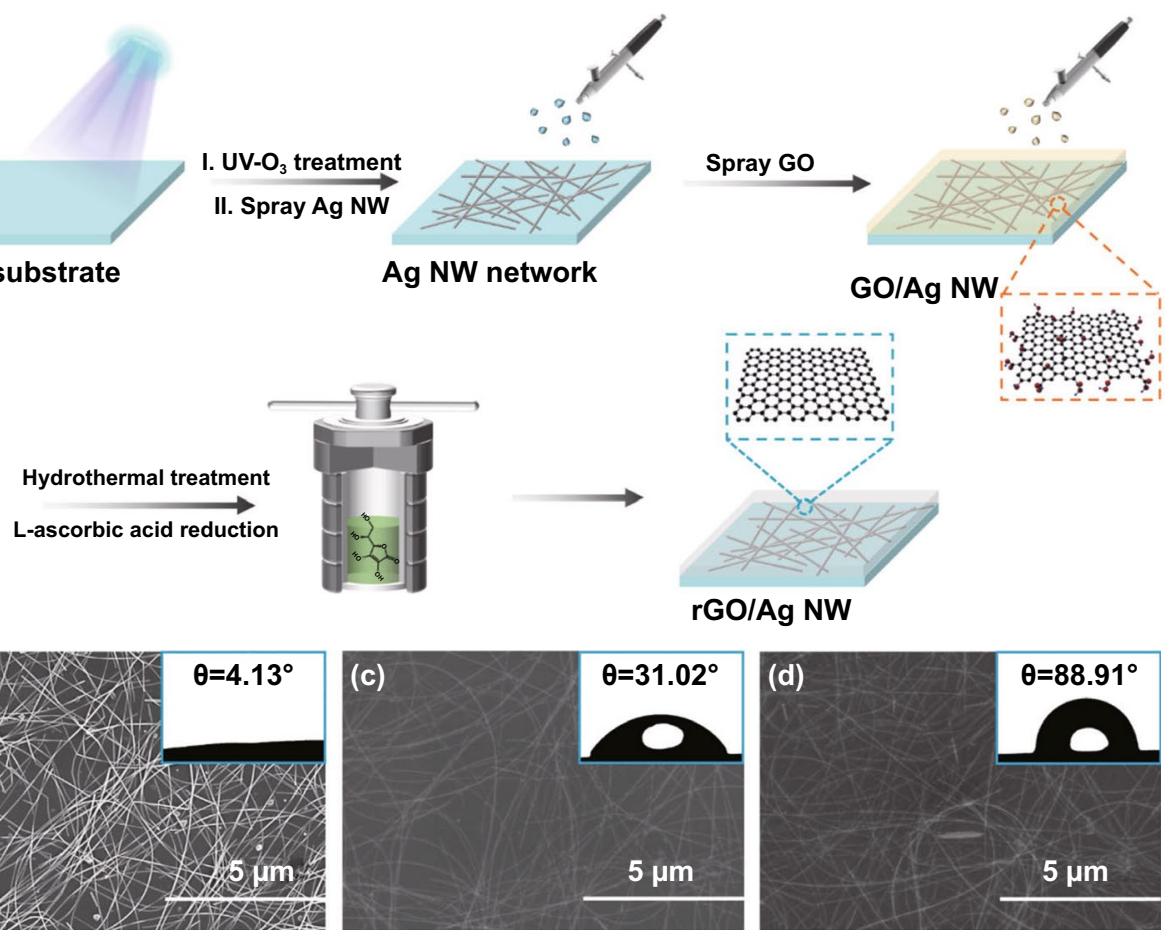

Fig. 1 a Schematic illustration of the fabrication procedure of rGO/Ag NW film. b-d SEM images of the Ag NW, GO/Ag NW, rGO/Ag NW films. The insets are the water contact angle of the corresponding films 
Raman spectra of Ag NW, GO/Ag NW, and rGO/Ag NW are given in Fig. S2b and 2c. The $I_{\mathrm{D}} / I_{\mathrm{G}}$ value of the GO/Ag NW is 1.09 , and that of the $\mathrm{rGO} / \mathrm{Ag} \mathrm{NW}$ increases to 1.34 . The intensity of $\mathrm{D}$ band became stronger after reduction, indicating that numerous defects were generated during reduction process, which is beneficial to promote the dissipation of electromagnetic wave $[29,30]$.

The XPS spectra are shown in Fig. 2d. Both GO/Ag NW and $\mathrm{rGO} / \mathrm{Ag} \mathrm{NW}$ present $\mathrm{C} 1 \mathrm{~s}, \mathrm{O} 1 \mathrm{~s}$, and $\mathrm{Ag} 3 \mathrm{~d}$ peaks. The $\mathrm{C} 1 \mathrm{~s}$ spectra further proved the reduction before and after adding L-ascorbic acid, as given in Fig. 2e-f. The C 1s spectrum of GO can be curve-fit into two main peaks around 284.8 and $286.9 \mathrm{eV}$, which is related to $\mathrm{C}-\mathrm{C} / \mathrm{C}=\mathrm{C}$ and $\mathrm{C}-\mathrm{O}$ groups $[31,32]$. In terms of $\mathrm{rGO} / \mathrm{Ag} \mathrm{NW}$, the intensity of $\mathrm{C}-\mathrm{O}$ is dramatically decreased, which conformed that GO has been reduced by L-ascorbic acid.

The chemical reduction mechanism of GO includes twostep $\mathrm{S}_{\mathrm{N}} 2$ nucleophilic and subsequent thermal elimination reactions, as shown in Fig. $2 \mathrm{~g}$. The five-membered ring of L-ascorbic acid has a special dienol structure, enabling L-ascorbic acid with reducibility. The hydroxyl groups on the dienol structure are very active, which can dissociate
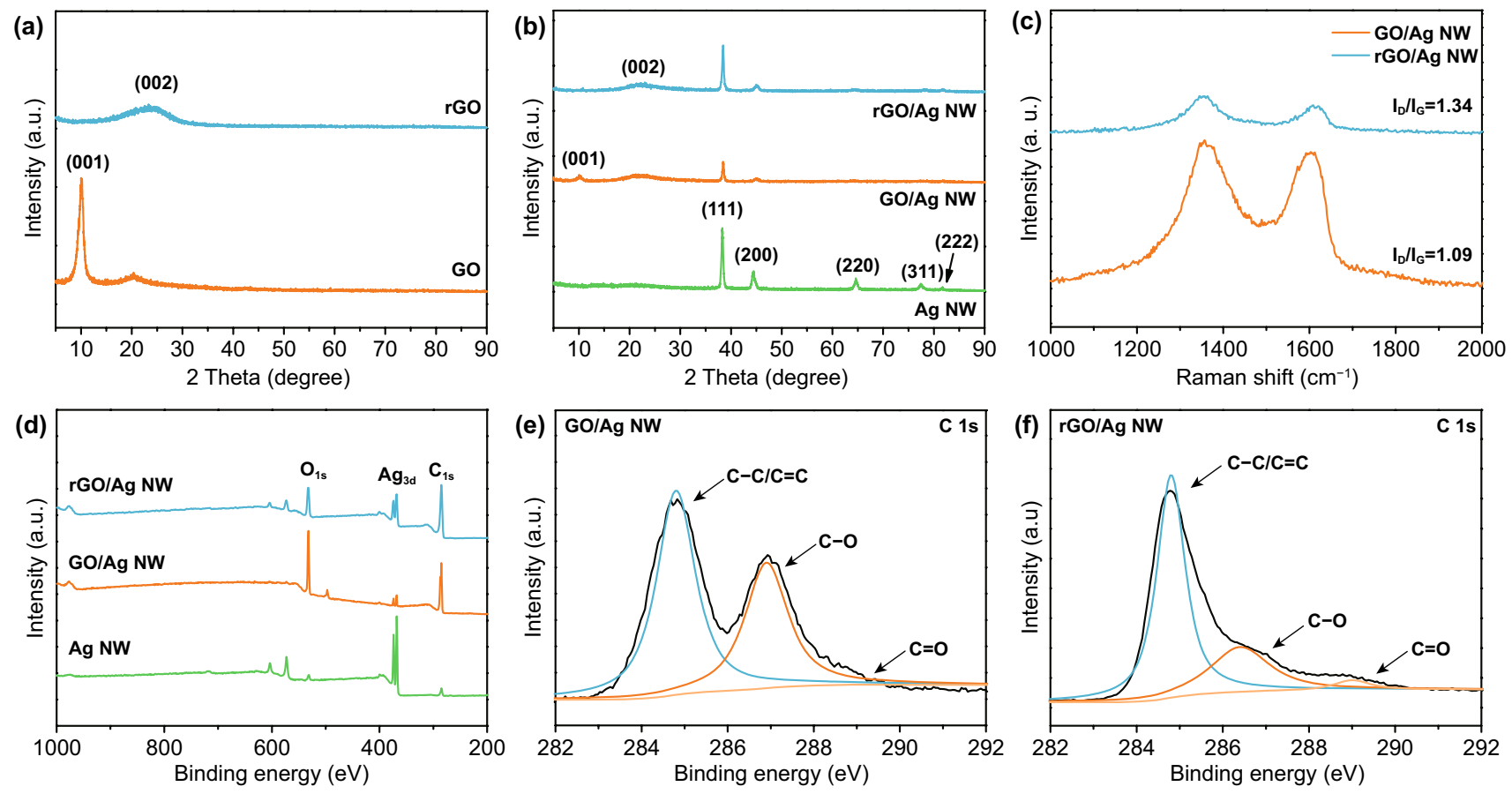

(g)

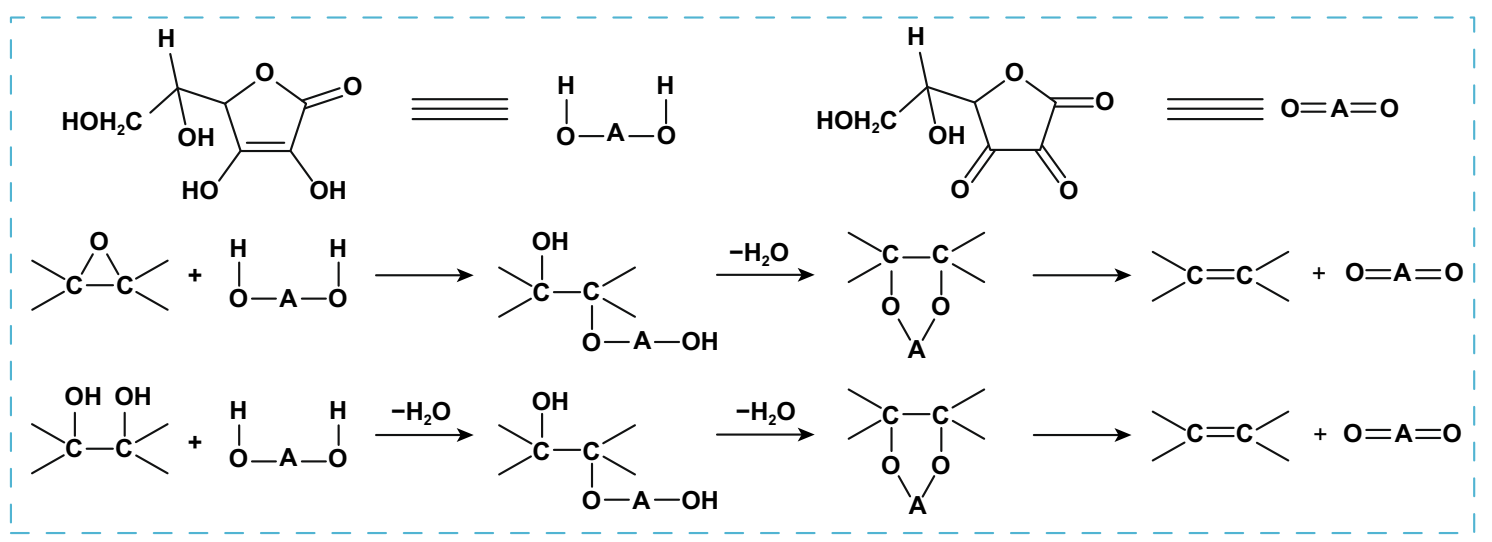

Fig. 2 a XRD pattern of GO and L-ascorbic acid reduced rGO. b XRD pattern of resultant Ag NW, GO/Ag NW and rGO/Ag NW. c Raman spectra of the GO/Ag NW and rGO/Ag NW films. d XPS spectra of the Ag NW, GO/Ag NW and rGO/Ag NW films. e, f C 1s spectra of the GO/Ag NW and rGO/Ag NW films. g Reaction pathway for the chemical reduction of GO with L-ascorbic acid 
protons and generate ascorbic acid anion $\left(\mathrm{HOAO}^{-}\right)$. During reduction process, $\mathrm{HOAO}^{-}$functions as nucleophilic reagent to attack the epoxy and hydroxyl groups on GO nanosheets. For example, epoxy groups can be opened by $\mathrm{HOAO}^{-}$during a $\mathrm{S}_{\mathrm{N}} 2$ nucleophilic reaction. Then, another $\mathrm{HOAO}^{-}$attacks the hydroxyl groups by a back-side $\mathrm{S}_{\mathrm{N}} 2$ nucleophilic reaction, generating intermediate and $\mathrm{H}_{2} \mathrm{O}$. Finally, the intermediate can be thermally eliminated, forming reduced graphene oxide. The reduction process of hydroxyl groups is similar to that of epoxy groups [33].

\subsection{Optical Transmittance and Electrical Conductivity}

For transparent EMI shielding film, optical transmittance and electrical conductivity are critical indicators. As shown in Fig. 3a, single Ag NW network exhibits excellent optical transparency. The GO/Ag NW film shows the typical brownish yellow, which is derived from the color of the GO nanosheets. After hydrothermal treatment, the color of $\mathrm{rGO} /$ $\mathrm{Ag} \mathrm{NW}$ is further deepened but it also has a great visual effect in the range of visible light (Fig. 3b). The optical transmittance of $\mathrm{Ag} \mathrm{NW}, \mathrm{GO} / \mathrm{Ag} \mathrm{NW}$, and $\mathrm{rGO} / \mathrm{Ag} \mathrm{NW}$ is given in Figs. 3c and S3. As expected, the transmittance of single Ag NW films decreases with the increase in Ag NW loading density due to the enhancement of photons scattering and reflection [34]. The insets show the color change of GO suspension, and the color of it becomes darker after adding L-ascorbic acid. With the same Ag NW content, the transmittance of the resultant films decreases slightly after covering by GO, and it further decreases after the reduction process. Nevertheless, the optical transmittance remains above $80 \%$ at $550 \mathrm{~nm}$.

Figure $3 \mathrm{~d}$ shows the electrical conductivity of GO before and after reduction. For GO film, the sheet resistance is up to $2918 \mathrm{k} \Omega \mathrm{sq}^{-1}$, which can be regarded as an insulator, while that of rGO is $0.94 \mathrm{k} \Omega ~ s q^{-1}$. The enhancement of conductivity is attributed to the removal of oxygen-containing groups on the GO nanosheets and recovery of graphene $\pi$-conjugated structure. Figure $3 \mathrm{e}$ compares the sheet resistance of $\mathrm{Ag} \mathrm{NW}, \mathrm{GO} / \mathrm{Ag} \mathrm{NW}$, and $\mathrm{rGO} / \mathrm{Ag} \mathrm{NW}$ films. For $\mathrm{Ag}$ NW films, the sheet resistance only depends on the area density of Ag NW. The increase in Ag NW content gradually improves the conductive network, providing more paths for electrons transmission, thereby promoting the improvement of conductivity (Fig. S4a-c). The sheet resistance of the GO/
Ag NW films is lower than Ag NW films, and it further decreases after reduction treatment. From Fig. S4d-f, it can be seen that the uncovered area reduces with the increase in rGO content. It is sufficient to completely wrap the $\mathrm{Ag}$ NW network when the area density of rGO is $50 \mathrm{mg} \mathrm{m}^{-2}$. It is obviously that the conductivity of the hybrid films is better than that of the corresponding single Ag NW films. This phenomenon can be explained by the following reasons: (i) The two-dimensional materials have the welding effect on Ag NW junctions due to the capillary force; (ii) The rGO nanosheets fill the uncovered area of Ag NW network, providing local conductivity; (iii) The stacking of Ag NW network and rGO layer can be regarded as two resistors in parallel. The total resistance is lower than Ag NW and rGO, respectively. Sheet resistance versus optical transmittance at $550 \mathrm{~nm}$ for $\mathrm{rGO} / \mathrm{Ag} \mathrm{NW}$ films and previous reported Ag NW-based transparent conductive films are plotted in Fig. $3 f$ and Table $1[9,17,19,20,35-41]$. The rGO/Ag NW films combine the merits of high transmittance and low sheet resistance.

\subsection{EMI Shielding Performance}

The $\mathrm{rGO} / \mathrm{Ag}$ NW film combines high conductivity and excellent optical transmittance, which grants the promising prospects in the field of transparent EMI shielding film. It is well established that the desirable conductivity enables excellent EMI shielding capability [42]. As shown in Fig. 4a, the total EMI shielding efficiency $\left(\mathrm{SE}_{\mathrm{T}}\right)$ of the $\mathrm{Ag} \mathrm{NW}$ films is $15.71,19.43$, and $25.53 \mathrm{~dB}$ as the $\mathrm{Ag} \mathrm{NW}$ area density increases from 300 to $500 \mathrm{mg} \mathrm{m}^{-2}$. The welding effect of GO has a small contribution to the improvement of EMI shielding capability, and the resultant GO/Ag NW films show $\mathrm{SE}_{\mathrm{T}}$ value of 16.75, 20.62, and 27.46 dB (Fig. S5). Compared with the single $\mathrm{Ag} \mathrm{NW}$ and $\mathrm{GO} / \mathrm{Ag} \mathrm{NW}$ films, the $\mathrm{rGO} / \mathrm{Ag}$ NW films exhibit strong EMI shielding performance with $\mathrm{SE}_{\mathrm{T}}$ value of 18.38, 24.38, and $33.62 \mathrm{~dB}$, respectively. These results are consistent with the trend of conductivity.

The $\mathrm{SE}_{\mathrm{T}}, \mathrm{SE}_{\mathrm{A}}$, and $\mathrm{SE}_{\mathrm{R}}$ of the $\mathrm{Ag} \mathrm{NW}$ and $\mathrm{rGO} / \mathrm{Ag} \mathrm{NW}$ films are shown in Fig. $4 \mathrm{~b}-\mathrm{c}$. The reflection loss is originated from the interaction between carriers and incident EM waves. The higher amount of Ag NWs constructs a perfect conductive network, which provides more transmission path to promote the interaction between carriers and incident EM waves [43]. Similarly, the rGO nanosheets fill the holes 
(a)

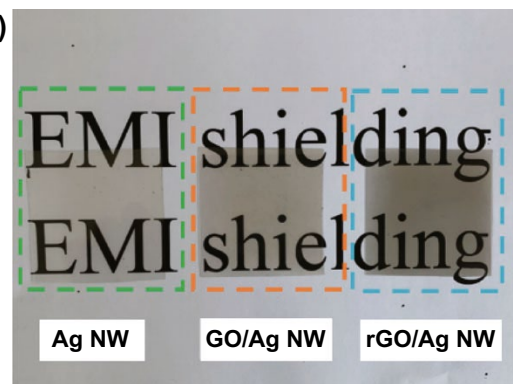

(d)

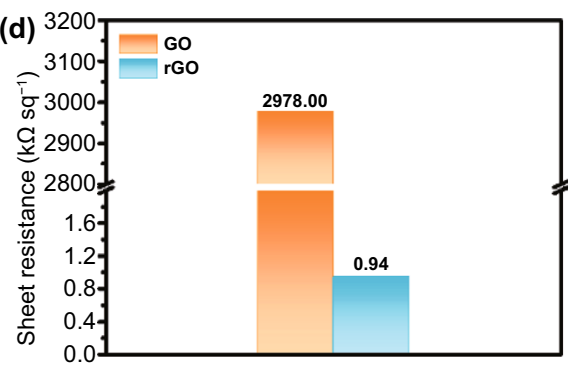

(b)
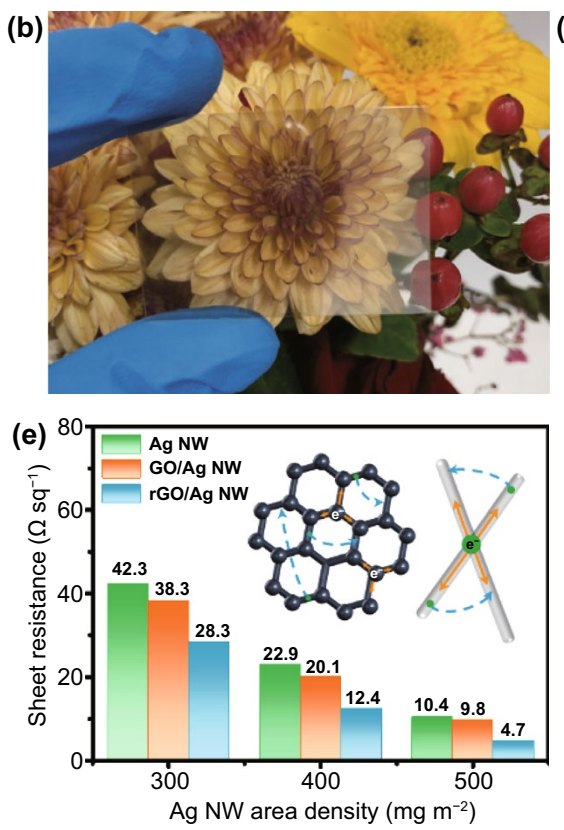
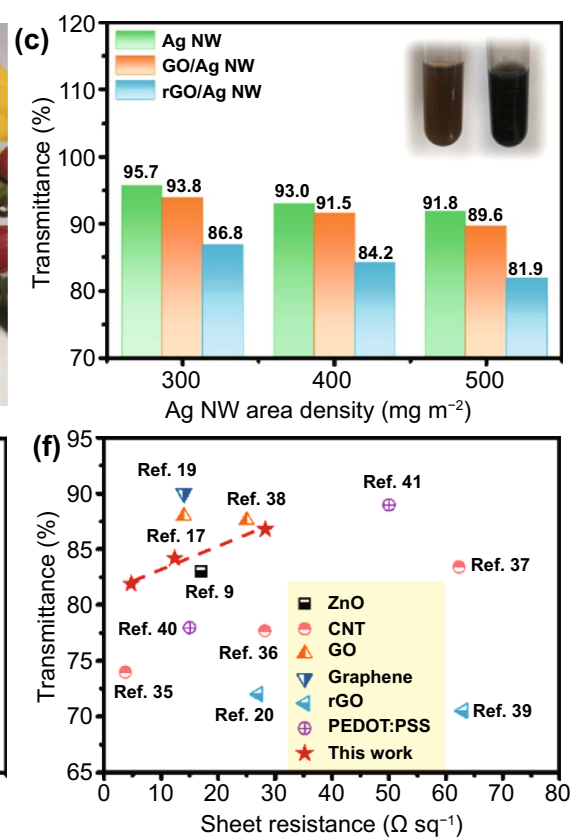

Fig. 3 a Digital images of the Ag NW, GO/Ag NW, and rGO/Ag NW films. The letters underneath the films are visible. b Visual effect of the rGO/Ag NW film. c Optical transmittance of prepared Ag NW, GO/Ag NW and rGO/Ag NW films. The insets are the GO (left) and rGO (right) suspension. d Sheet resistance of GO before and after reduced by L-ascorbic acid. e Sheet resistance of the Ag NW, GO/Ag NW and rGO/Ag NW films. f Comparison of sheet resistance-transmittance of the rGO/Ag NW films prepared in this work and other similar transparent EMI shielding films reported previously

of non-connect Ag NWs and provide additional electrical path. Compared with the Ag NW counterparts, both $\mathrm{SE}_{\mathrm{T}}$ and $\mathrm{SE}_{\mathrm{R}}$ of the $\mathrm{rGO} / \mathrm{Ag} \mathrm{NW}$ films are higher because of the enhanced conductivity. The Ag NW conductive network is conducive to induced current transmission upon alternating electric field, enabling an electromagnetic-thermal energy conversion [44]. With the increase in Ag NW, the value of $\mathrm{SE}_{\mathrm{A}}$ shows an upward trend due to the gradually improved conductive network. The introduction of rGO nanosheets constructs a more complete conductive network, which promotes the improvement of $\mathrm{SE}_{\mathrm{A}}$. In addition, the defects of $\mathrm{rGO}$ act as polarization centers, resulting in dipole polarization, thereby enhancing absorption loss [45].

To understand the underlying EMI shielding mechanism, the power coefficients of $\mathrm{R}, \mathrm{A}$, and $\mathrm{T}$ are plotted in Fig. 4d. With the increase in Ag NW loadings, the value of T changes little, while the value of $\mathrm{R}$ shows an obvious upward trend due to the formation of gradually improved conductive network. The $\mathrm{R}$ value of $\mathrm{rGO} / \mathrm{Ag} \mathrm{NW}$ is higher than that of the $\mathrm{Ag} \mathrm{NW}$, which is related to the enhancement of conductivity. The value of A exhibits a downward trend, and the amount of power shielded by absorption is lower than that of
Table 1 Sheet resistance and optical transmittance of Ag NW-based transparent conductive films

\begin{tabular}{llll}
\hline Materials & $\mathrm{T}(\%)$ & $\mathrm{Rs}\left(\Omega \mathrm{sq}^{-1}\right)$ & References \\
\hline Ag NW/FZO & 83 & 17 & {$[9]$} \\
Ag NW/SWCNT & 74 & 3.7 & {$[35]$} \\
Ag NW/SWCNT & 77.7 & 28.2 & {$[36]$} \\
Ag NW/SWCNT & 83.4 & 62.3 & {$[37]$} \\
GO/Ag NW & 88 & 14 & {$[17]$} \\
GO/Ag NW & 87.6 & 25 & {$[38]$} \\
Ag NW/graphene & 90 & 14 & {$[19]$} \\
Ag NW/rGO & 72 & 27 & {$[20]$} \\
Ag NW/rGO & 70.5 & 63 & {$[39]$} \\
Ag NW/PEDOT:PSS & 78 & 15 & {$[40]$} \\
Ag NW/PEDOT:PSS & 89 & 50 & {$[41]$} \\
rGO/Ag NW & 86.8 & 28.3 & This work \\
& 84.2 & 12.4 & \\
\hline
\end{tabular}

FZO: fluorine-doped $\mathrm{ZnO}$; SWCNT: single-walled carbon nanotube; PEDOT: PSS: poly (3, 4-ethylenedioxythiophene): polystyrenesulfonate 

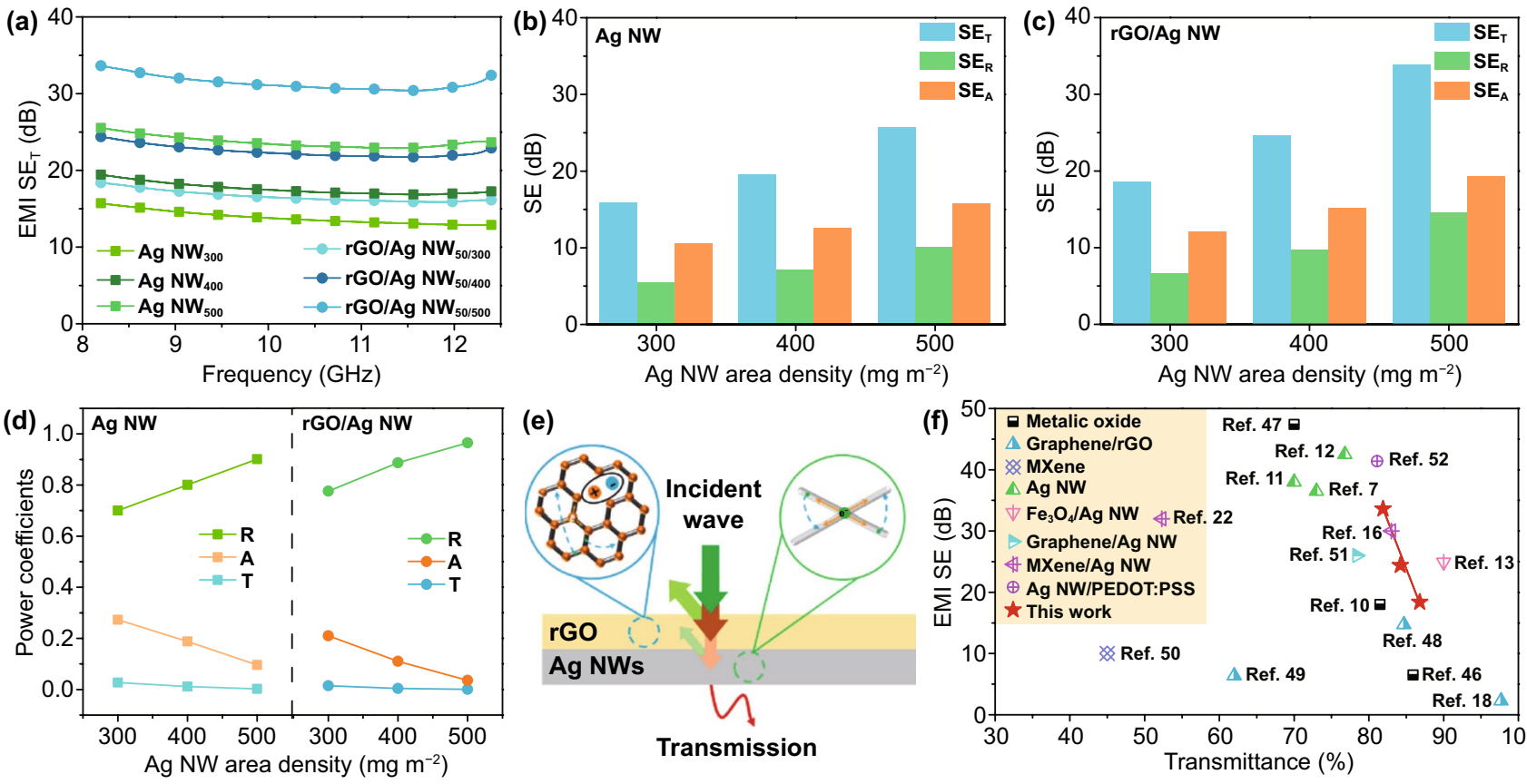

(e)

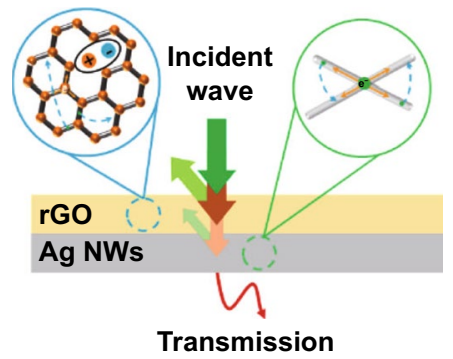

(h)

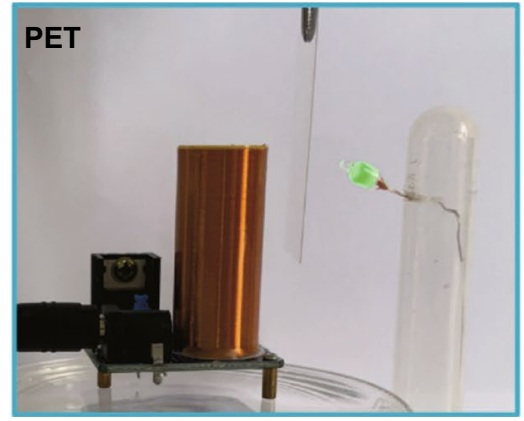

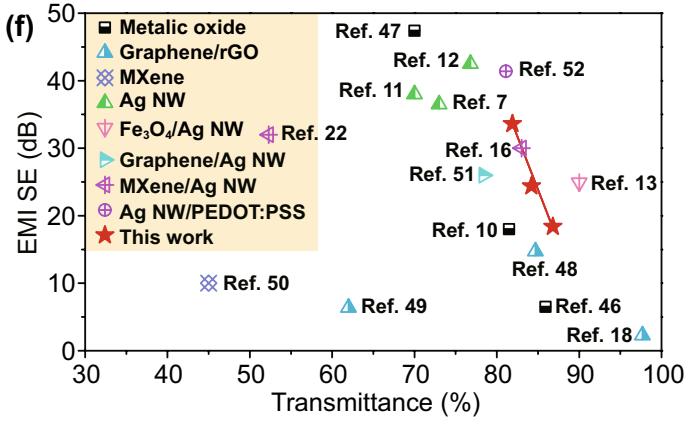

(i)

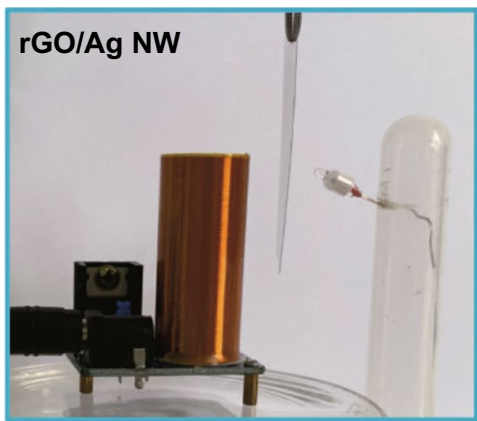

Fig. 4 a The EMI $\mathrm{SE}_{\mathrm{T}}$ of the $\mathrm{Ag} \mathrm{NW}$ and $\mathrm{rGO} / \mathrm{Ag} \mathrm{NW}$ films. $\mathbf{b} \mathrm{SE}_{\mathrm{T}}, \mathrm{SE}_{\mathrm{R}}$ and $\mathrm{SE}_{\mathrm{A}}$ of the $\mathrm{Ag} \mathrm{NW}$ films. $\mathrm{c} \mathrm{SE}_{\mathrm{T}}, \mathrm{SE}_{\mathrm{R}}$ and $\mathrm{SE}_{\mathrm{A}}$ of the $\mathrm{rGO} / \mathrm{Ag}$ NW films. d Power coefficients of the Ag NW and rGO/Ag NW films. e Schematic of the EMI shielding mechanisms of the rGO/Ag NW film. $f$ Comparison of optical transmittance-EMI shielding performance of this work with similar work reported recently. g-i Digital images of wireless power transfer circuit to demonstrate the EMI shielding application of the $\mathrm{rGO} / \mathrm{Ag} \mathrm{NW}$ film

reflection. Generally, the improvement of conductivity also enhances the absorption loss. Here, we introduce the effective absorption coefficient $\left(\mathrm{A}_{\text {eff }}, A_{\text {eff }}=\frac{1-R-T}{1-R}\right)$ to evaluate the effective contribution of absorption loss, which shown in Fig. S6. As expected, the value of $A_{\text {eff }}$ increases with increase in $\mathrm{Ag} \mathrm{NW}$ content and the introduction of rGO. Overall, the growth of $\mathrm{R}$ is greater than that of $\mathrm{A}$. Thus, $\mathrm{A}$ shows a downward trend. According to the analysis above, the dominant EMI shielding mechanism of the Ag NW and $\mathrm{rGO} / \mathrm{Ag} \mathrm{NW}$ films is reflection. Based on transmission line theory, the EM wave transfer process is demonstrated as follows (Fig. 4e). First, most incident EM waves were reflected at the shield-air interface because of impedance mismatching. High concentration of carries interacted with EM waves, resulting in strong reflection loss. Second, the electromagnetic energy can be converted into thermal energy via conduction loss and dipole polarization, which contributes to absorption loss. Finally, the residual EM waves continue to transmit through the shield.

To highlight the merits of our work, the comparison of the optical transmittance and EMI shielding performance of this work and similar transparent EMI shielding films are shown in Fig. 4f and Table 2 [7, 10-13, 16, 18, 22, 46-52]. It can be found that the comprehensive performance of $\mathrm{rGO} /$ Ag NW films is superior than most of reported literature works. These results indicate that the $\mathrm{rGO} / \mathrm{Ag} \mathrm{NW}$ films are 
promising candidates for ideal transparent EMI shielding application.

A wireless power transmission device was used to demonstrate the EM waves blocking effect of $\mathrm{rGO} / \mathrm{Ag} \mathrm{NW}$, as shown in Fig. 4g-i and Movie S1. When the power supply is turned on, it can drive the LED bulb to light up whether or not inserting pristine electrical insulating PET substrate. On the contrary, the LED bulb extinguished when inserting the $\mathrm{rGO} / \mathrm{Ag}$ NW film, suggesting that the wireless transmission has been blocked.

\subsection{Mechanical Performance and Chemical Stability}

In addition to high optical transmittance and strong EMI shielding capability, mechanical flexibility and reliable durability are important preconditions for the application in the field of flexible electronics. As shown in Fig. 5a, the EMI $\mathrm{SE}_{\mathrm{T}}$ value of $\mathrm{Ag} \mathrm{NW_{500 }}$ shows an obvious downward trend during cyclic bending test. Compared with the original, the Ag NW network deforms severely, and most Ag NWs were broken after repeated bending. The conductive network has been destroyed, leading to EMI shielding performance degradation. In contrast, the $\mathrm{rGO} / \mathrm{Ag} \mathrm{NW} \mathrm{N}_{50 / 500}$ shows a stable EMI shielding performance under numerous deformations (Fig. 5b). The rGO/Ag NW network presents intact structure, with some cracks on the surface after bending, resulting in EMI shielding performance down slightly. The ratio of $\mathrm{SE}$ to original $\mathrm{SE}\left(\mathrm{SE} / \mathrm{SE}_{\mathrm{O}}\right.$ ) was calculated to evaluate the stability and reliability of repeated straightening-bending cycles. The $\mathrm{SE} / \mathrm{SE}_{\mathrm{O}}$ of the $\mathrm{rGO} / \mathrm{Ag} \mathrm{NW}$ is 0.96 , while that of the Ag NW is only 0.66 after bending for 1000 times. (Fig. 5c). Therefore, compared with the Ag NW counterpart, the $\mathrm{rGO}$ can bridge the fragmented $\mathrm{Ag} \mathrm{NW}$ and protect it from slippage, showing a remarkable fatigue resistance upon bending deformation.

The Ag NW is prone to be oxidized if exposed to air. As shown in Fig. 5d inset, numerous oxidized particles appear on the surface of $\mathrm{Ag} \mathrm{NWs}$ after exposing in air for 80 days. Wrapping by rGO nanosheets, the structure of Ag NW network remains intact for a long time. Changes in EMI SE have been recorded every 20 days to evaluate the chemical stability of Ag NW and rGO/Ag NW film (Fig. 5d). After exposing in air for 80 days, the EMI SE of $\mathrm{rGO} / \mathrm{Ag}$ $\mathrm{NW}_{50 / 500}$ decreases slightly from 33.62 to $30.37 \mathrm{~dB}$, whereas
Table 2 Comparison of optical transmittance and EMI shielding performance of transparent EMI shielding films

\begin{tabular}{lllll}
\hline Materials & Substrate & $\mathrm{T}(\%)$ & $\mathrm{SE}(\mathrm{dB})$ & References \\
\hline ITO & Glass & 81.5 & $\sim 18$ & {$[10]$} \\
$\mathrm{Al}-\mathrm{ZnO}$ & Glass & 85.93 & 6.5 & {$[46]$} \\
Ga-ZnO & Glass & 70 & 47.4 & {$[47]$} \\
Monolayer graphene & PET & 97.7 & 2.27 & {$[18]$} \\
Multilayer graphene & PET & 84.7 & 14.73 & {$[48]$} \\
rGO & PEI & 62 & 6.37 & {$[49]$} \\
MXene & Glass & 45 & 10 & {$[50]$} \\
PES/Ag NW & PET & 70 & 38 & {$[11]$} \\
CA/Ag NW & PU & 73 & 36.5 & {$[7]$} \\
Ag NW & PDMS & 76.8 & 42.5 & {$[12]$} \\
Fe ${ }_{3}$ /Ag NW & PET & 90 & 24.9 & {$[13]$} \\
Graphene/Ag NW & Glass & 78.4 & 26 & {$[51]$} \\
Ag NW/MXene & PET & 83 & $\sim 30$ & {$[16]$} \\
Ag NW/MXene/PVA & PC & 52.3 & 32 & {$[22]$} \\
Ag NW/PEDOT: PSS & Glass & 81.1 & 41.4 & {$[52]$} \\
rGO/Ag NW & PET & 86.8 & 18.38 & This work \\
& & 84.2 & 24.38 & \\
& & 81.9 & 33.62 & \\
\hline
\end{tabular}

PEI: poly (ethylene imine); PES: poly (ethersulfones); CA: calcium alginate; PU: polyurethane; PVA: polyvinyl alcohol; PC: polycarbonate

that of the counterpart declines significantly from 25.53 to $12.51 \mathrm{~dB}$. The rGO coating prevents the direct contact between $\mathrm{Ag} \mathrm{NW}$ and air, enhancing long-time environment stability.

\subsection{Electrical Heating Performance and Thermal Stability}

According to our previous work, ice crystals are generated on the surface of PET substrate below $0{ }^{\circ} \mathrm{C}$, leading to unsatisfactory optical transmittance [34]. The electro-thermal ability of transparent EMI shielding films is expected to realize thermal regulation and anti-frozen. In this work, we investigate the surface temperature $\left(\mathrm{T}_{\mathrm{S}}\right)$ of the $\mathrm{Ag} \mathrm{NW}$ and $\mathrm{rGO} / \mathrm{Ag} \mathrm{NW}$ films based on Joule heating effect $\left(Q=\frac{U^{2}}{R} t\right.$, where $\mathrm{Q}, \mathrm{U}, \mathrm{R}$, and $\mathrm{t}$ represent heat, applied voltage, resistance of EMI shielding film, and time). As shown in Fig. S7a$\mathrm{b}$, the maximum $\mathrm{Ts}$ of $\mathrm{Ag} \mathrm{NW} \mathrm{NW}_{300}$ and $\mathrm{Ag} \mathrm{NW} \mathrm{NW}_{500}$ is about $50^{\circ} \mathrm{C}$. It was reported that the melting temperature decreases significantly if the size of Ag reduces to nanoscale. For bulk 

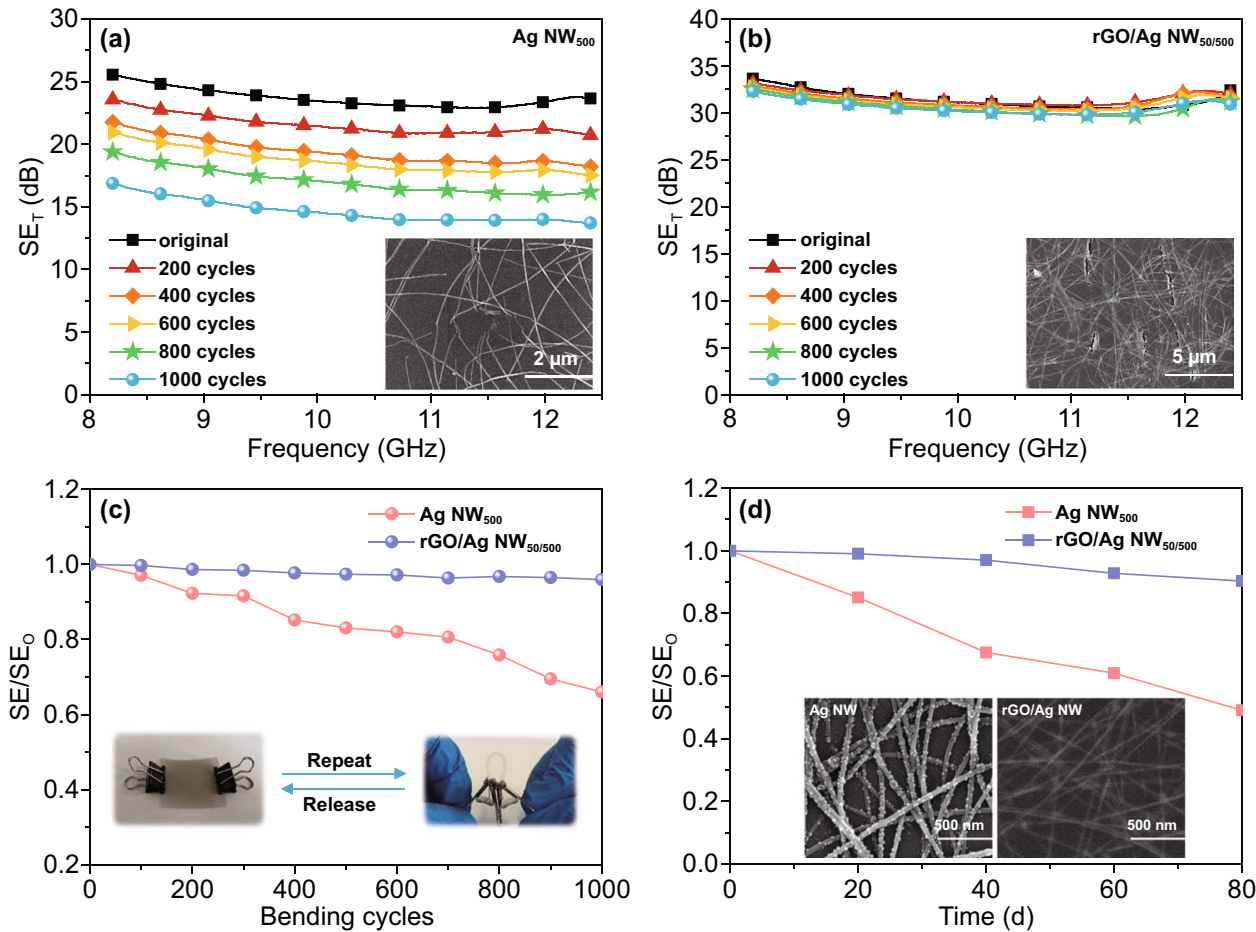

Fig. 5 a, b Change in $\mathrm{SE}_{\mathrm{T}}$ of the $\mathrm{Ag} \mathrm{NW}$ and $\mathrm{rGO} / \mathrm{Ag} \mathrm{NW}$ films with various numbers of bending cycles. Insets are SEM images of the Ag NW and $\mathrm{rGO} / \mathrm{Ag} \mathrm{NW}$ films after 1000 times cyclic bending. $\mathrm{c}$ EMI SE variation in the Ag NW and $\mathrm{rGO} / \mathrm{Ag} \mathrm{NW}$ films during cyclic bending test. The insets are home-made bending test equipment and the bending radius is $2 \mathrm{~mm}$. d EMI SE variation in the $\mathrm{Ag} \mathrm{NW}$ and $\mathrm{rGO} / \mathrm{Ag} \mathrm{NW}$ films during long-time exposure in air at room temperature. Insets are SEM images of the Ag NW and rGO/Ag NW films after long-time oxidation

$\mathrm{Ag}$, the melting temperature is up to $960{ }^{\circ} \mathrm{C}$, while that of the Ag NW is only $200{ }^{\circ} \mathrm{C}[53,54]$. For Ag NW conductive network, the current is transmitted between nanowires when voltage is applied. Due to the high contact resistance, the generated heat accumulates at the junctions of $\mathrm{Ag} \mathrm{NW}$, and the local temperature could reach over $300{ }^{\circ} \mathrm{C}$, resulting in electrical failure [55]. It can be seen that the junctions of $\mathrm{Ag}$ NW were fused at high voltages, leading to the fracture of conductive network (Fig. S7c-d).

Figure $6 \mathrm{a}-\mathrm{c}$ shows temperature-time profiles of $\mathrm{rGO} /$ $\mathrm{Ag}$ NW films at different applied voltages. The Ts of all specimens increases with the increase in applied voltages. Besides, the films with lower sheet resistance have higher Ts at the same external voltage. For example, at the voltage of $4 \mathrm{~V}$, the Ts of $\mathrm{rGO} / \mathrm{Ag} \mathrm{NW} \mathrm{No/300}$ is $39.8^{\circ} \mathrm{C}$, whereas that of $\mathrm{rGO} / \mathrm{Ag} \mathrm{NW} \mathrm{N}_{50 / 500}$ is $56.1^{\circ} \mathrm{C}$. In conclusion, an ideal electric heater can achieve high Ts and realize fast temperature response at low driving voltage. Besides, the introduction of $\mathrm{rGO}$ reduces the contact resistance and disperses heat into the substrate and air, which is beneficial to improve the thermal stability of $\mathrm{rGO} / \mathrm{Ag} \mathrm{NW}$. For instance, the highest $\mathrm{T}_{\mathrm{S}}$ of $\mathrm{rGO} / \mathrm{Ag} \mathrm{NW} \mathrm{N}_{50 / 300}$ is up to $83.3{ }^{\circ} \mathrm{C}$, while that of $\mathrm{Ag}$ $\mathrm{NW}_{300}$ is only $51.6^{\circ} \mathrm{C}$. It should be noted that the highest $\mathrm{T}_{\mathrm{S}}$ of $\mathrm{rGO} / \mathrm{Ag} \mathrm{NW} \mathrm{N}_{50 / 500}$ is similar to the $\mathrm{Ag} \mathrm{NW}_{500}$, suggesting that a small amount of rGO has little effect on the improvement of thermal stability.

Given the Ts of Ag NW films and $\mathrm{rGO} / \mathrm{Ag} \mathrm{NW} \mathrm{N}_{50 / 500}$ can only reach about $50-60{ }^{\circ} \mathrm{C}$, this work focused on the Ts variation in $\mathrm{rGO} / \mathrm{Ag} \mathrm{NW} \mathrm{N}_{50 / 300}$ and $\mathrm{rGO} / \mathrm{Ag} \mathrm{NW}_{50 / 400}$. Figure $6 \mathrm{~d}$, $\mathrm{g}$ shows the tailored Ts of the $\mathrm{rGO} / \mathrm{Ag} \mathrm{NW} \mathrm{N}_{50 / 300}$ and $\mathrm{rGO} /$ $\mathrm{Ag} \mathrm{NW} \mathrm{S0/400}$ upon stepwise voltages. The real-time temperature ascends or descends with the increase or decrease in operation voltages, indicating thermal regulation capability of rGO/Ag NW films. The repeated heating cycles and long-time heating tests at constant voltage were carried out to estimate the thermal stability and repeatability of $\mathrm{rGO} / \mathrm{Ag}$ NW films. We chose 9.0 and $6.0 \mathrm{~V}$ as the applied voltage of $\mathrm{rGO} / \mathrm{Ag} \mathrm{NW}_{50 / 300}$ and $\mathrm{rGO} / \mathrm{Ag} \mathrm{NW}_{50 / 400}$, respectively. Under 
these voltages, the Ts of $\mathrm{rGO} / \mathrm{Ag} \mathrm{NW}$ films exceeds $60{ }^{\circ} \mathrm{C}$. At the voltage of $9.0 \mathrm{~V}$, the highest temperature of $\mathrm{rGO} /$ Ag NW 50/300 maintains ca. $64.1{ }^{\circ} \mathrm{C}$ during repeated on-off cycle heating process (Fig. 6e). Similarly, the highest temperature of $\mathrm{rGO} / \mathrm{Ag} \mathrm{NW} \mathrm{NO}_{50 / 400}$ maintains ca. $73.8^{\circ} \mathrm{C}$ at $6.0 \mathrm{~V}$ (Fig. 6h). Figure 6f, i shows the long-time thermal stability of rGO/Ag NW films with $\mathrm{Ag} \mathrm{NW}$ loading density of 300 and $400 \mathrm{mg} \mathrm{m}^{-2}$. The Ts of $\mathrm{rGO} / \mathrm{Ag} \mathrm{NW}_{50 / 300}$ and $\mathrm{rGO} / \mathrm{Ag}$ $\mathrm{NW}_{50 / 400}$ fluctuates slightly for heating $1 \mathrm{~h}$, indicating these electrical heaters possess excellent thermal stability. The insets are IR images of $\mathrm{rGO} / \mathrm{Ag} \mathrm{NW} \mathrm{N0/300}$ at $9.0 \mathrm{~V}$ and $\mathrm{rGO} /$ $\mathrm{Ag} \mathrm{NW} \mathrm{N}_{5 / 400}$ at $6.0 \mathrm{~V}$, which exhibit uniform temperature distribution.

\section{Conclusion}

In summary, we proposed a facile method, including spraycoating and L-ascorbic acid reduction process, to fabricate flexible transparent $\mathrm{rGO} / \mathrm{Ag} \mathrm{NW}$ films. Compared with the Ag NW films, the introduction of rGO improves the overall conductivity. The resultant $\mathrm{rGO} / \mathrm{Ag} \mathrm{NW}$ film exhibits outstanding EMI SE of $33.62 \mathrm{~dB}$ with an optical transmittance of $81.9 \%$. Besides, the EMI shielding performance of rGO/Ag NW has no obvious degradation after 1000 times bending cycles and long-time exposure in air, presenting reliable durability and outstanding stability. Moreover, the (a)
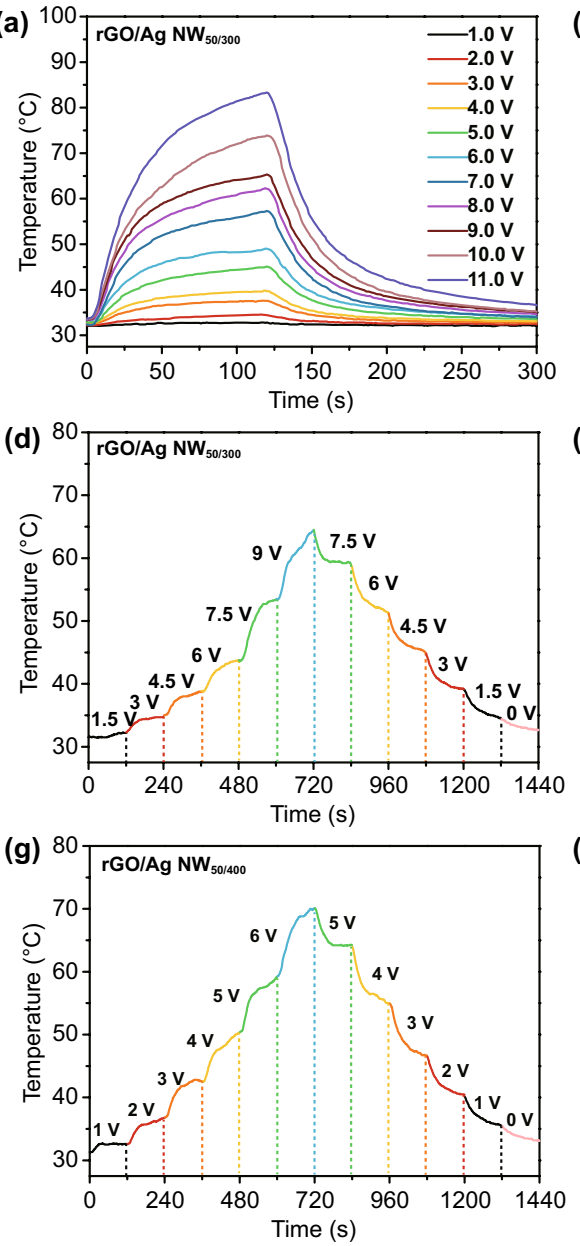
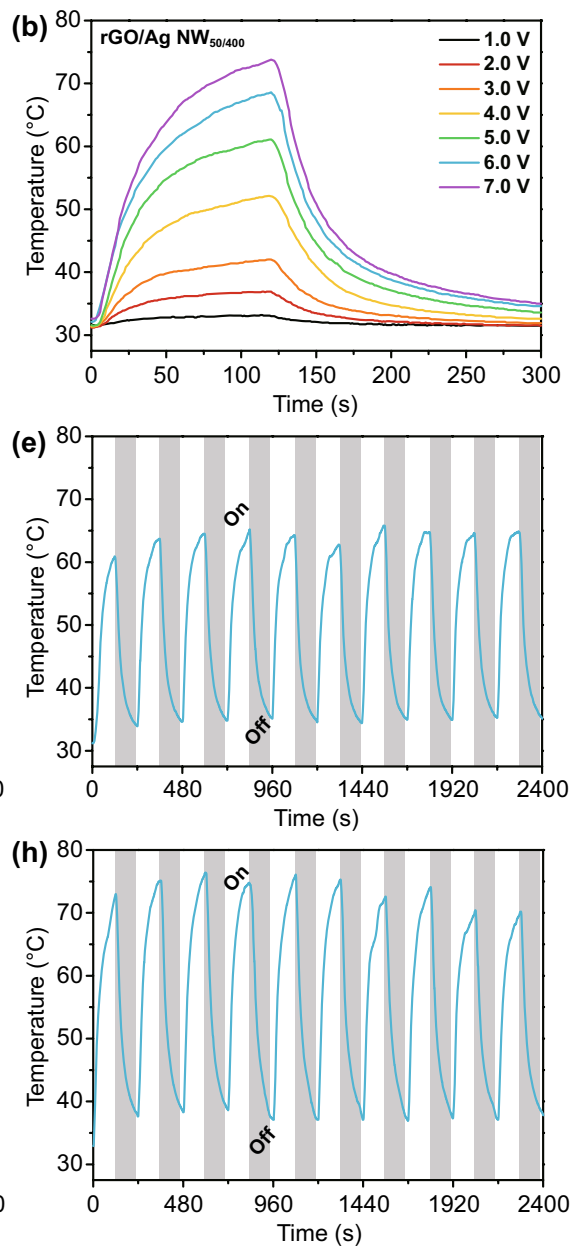
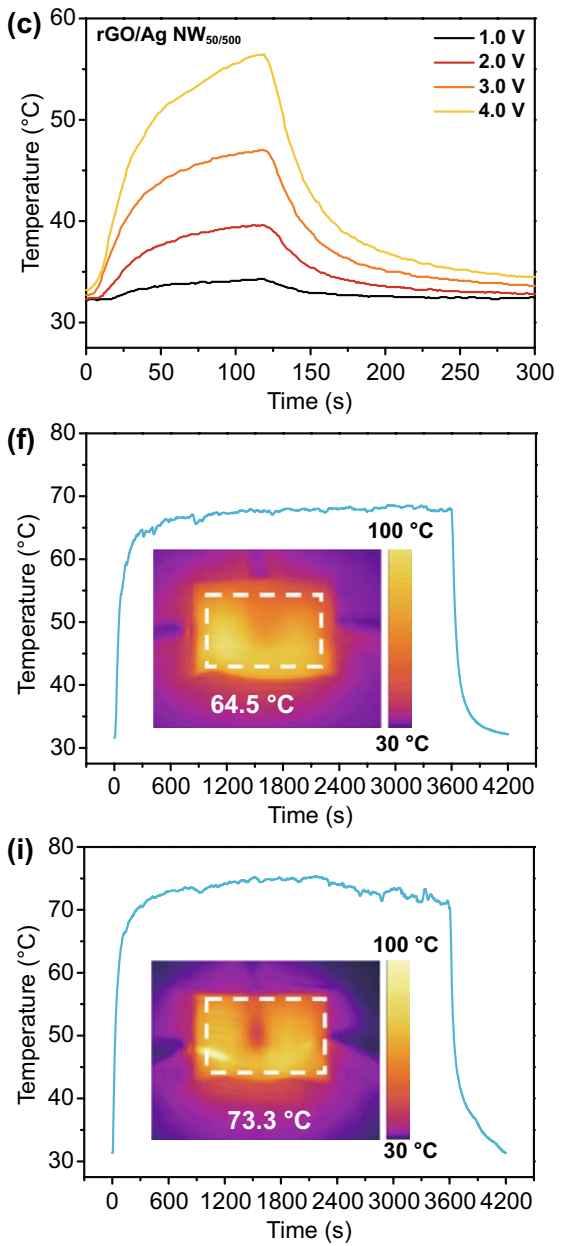

Fig. 6 a-c Temperature-time profiles of the rGO/Ag NW $\mathrm{N}_{50 / 300}$, rGO/Ag NW $\mathrm{N}_{50 / 400}$, and $\mathrm{rGO} / \mathrm{Ag} \mathrm{NW} \mathrm{N}_{50 / 500}$ at different applied voltages. d Tailored surface temperature of the $\mathrm{rGO} / \mathrm{Ag} \mathrm{NW} \mathrm{NW}_{500}$ upon stepwise voltages. e Heating cycles of the $\mathrm{rGO} / \mathrm{Ag} \mathrm{NW}_{50 / 300}$ upon repeated applied voltage of $9.0 \mathrm{~V}$. f Electrical heating time-temperature curve at a constant voltage of $9.0 \mathrm{~V}$ for $1 \mathrm{~h}$. The inset is IR image of $\mathrm{rGO} / \mathrm{Ag} \mathrm{NW}_{50 / 300}$ at $9.0 \mathrm{~V}$. $\mathbf{g}$ Tailored surface temperature of the $\mathrm{rGO} / \mathrm{Ag} \mathrm{NW} \mathrm{N}_{5 / 400}$ upon stepwise voltages. $\mathbf{h}$ Heating cycles of the $\mathrm{rGO}_{\mathrm{Ag} \mathrm{NW}} \mathrm{N}_{50 / 400}$ upon repeated applied voltage of $6.0 \mathrm{~V}$. i Electrical heating time-temperature curve at a constant voltage of $6.0 \mathrm{~V}$ for $1 \mathrm{~h}$. The inset is IR image of rGO/Ag $\mathrm{NW}_{50 / 400}$ at $6.0 \mathrm{~V}$ 
transparent EMI shielding films possess the fast thermal response and thermal stability. The integrated multifunction endows the $\mathrm{rGO} / \mathrm{Ag} \mathrm{NW}$ films with huge potential for the application of next-generation flexible and wearable electronics.

Acknowledgements Financial support from National Nature Science Foundation of China (51971111), the Foundation of Graduate Innovation Center in NUAA (kfjj20200602) is gratefully acknowledged.

Funding Open access funding provided by Shanghai Jiao Tong University.

Open Access This article is licensed under a Creative Commons Attribution 4.0 International License, which permits use, sharing, adaptation, distribution and reproduction in any medium or format, as long as you give appropriate credit to the original author(s) and the source, provide a link to the Creative Commons licence, and indicate if changes were made. The images or other third party material in this article are included in the article's Creative Commons licence, unless indicated otherwise in a credit line to the material. If material is not included in the article's Creative Commons licence and your intended use is not permitted by statutory regulation or exceeds the permitted use, you will need to obtain permission directly from the copyright holder. To view a copy of this licence, visit http://creativecommons.org/licenses/by/4.0/.

Supplementary Information The online version contains supplementary material available at https://doi.org/10.1007/ s40820-022-00810-y.

\section{References}

1. L. Liang, W. Gu, Y. Wu, B. Zhang, G. Wang et al., Heterointerface engineering in electromagnetic absorbers: new insights and opportunities. Adv. Mater. (2021). https://doi.org/10.1002/ adma.202106195

2. L. Su, J. Ma, F. Zhang, Y. Fan, W. Luo et al., Achieving effective broadband microwave absorption with $\mathrm{Fe}_{3} \mathrm{O}_{4} @ \mathrm{C}$ supraparticles. J. Materiomics 7(1), 80-88 (2021). https://doi.org/ 10.1016/j.jmat.2020.07.011

3. X. Zhou, Z. Jia, X. Zhang, B. Wang, X. Liu et al., Electromagnetic wave absorption performance of $\mathrm{NiCo}_{2} \mathrm{X}_{4}(\mathrm{X}=\mathrm{O}, \mathrm{S}$, $\mathrm{Se}, \mathrm{Te})$ spinel structures. Chem. Eng. J. 420, 129907 (2021). https://doi.org/10.1016/j.cej.2021.129907

4. B. Yao, W. Hong, T. Chen, Z. Han, X. Xu et al., Highly stretchable polymer composite with strain-enhanced electromagnetic interference shielding effectiveness. Adv. Mater. 32(14), 1907499 (2020). https://doi.org/10.1002/adma.201907499

5. Z. Chen, C. Xu, C. Ma, W. Ren, H.M. Cheng, Lightweight and flexible graphene foam composites for high-performance electromagnetic interference shielding. Adv. Mater. 25(9), 1296-1300 (2013). https://doi.org/10.1002/adma.201204196

6. Y. Zhao, L.L. Hao, X.D. Zhang, S.J. Tan, H.H. Li et al., A Novel strategy in electromagnetic wave absorbing and shielding materials design: multi-responsive fields effect. Small Sci. (2021). https://doi.org/10.1002/smsc.202100077

7. L.C. Jia, D.X. Yan, X. Liu, R. Ma, H.Y. Wu et al., Highly efficient and reliable transparent electromagnetic interference shielding film. ACS Appl. Mater. Interfaces 10(14), 1194111949 (2018). https://doi.org/10.1021/acsami.8b00492

8. C. Yuan, J. Huang, Y. Dong, X. Huang, Y. Lu et al., Recordhigh transparent electromagnetic interference shielding achieved by simultaneous microwave fabry-pérot interference and optical antireflection. ACS Appl. Mater. Interfaces 12(23), 26659-26669 (2020). https://doi.org/10.1021/acsami.0c05334

9. J. Han, S. Yuan, L. Liu, X. Qiu, H. Gong et al., Fully indiumfree flexible Ag nanowires/ZnO: F composite transparent conductive electrodes with high haze. J. Mater. Chem. A 3(10), 5375-5384 (2015). https://doi.org/10.1039/c4ta05728g

10. Y. Han, H. Zhong, N. Liu, Y. Liu, J. Lin et al., In situ surface oxidized copper mesh electrodes for high-performance transparent electrical heating and electromagnetic interference shielding. Adv. Electron. Mater. 4(11), 1800156 (2018). https://doi.org/10.1002/aelm.201800156

11. M. Hu, J. Gao, Y. Dong, K. Li, G. Shan et al., Flexible transparent PES/silver nanowires/PET sandwich-structured film for high-efficiency electromagnetic interference shielding. Langmuir 28(18), 7101-7106 (2012). https://doi.org/10.1021/la300 $720 \mathrm{y}$

12. J. Jung, H. Lee, I. Ha, H. Cho, K.K. Kim et al., Highly stretchable and transparent electromagnetic interference shielding film based on silver nanowire percolation network for wearable electronics applications. ACS Appl. Mater. Interfaces 9(51), 44609-44616 (2017). https://doi.org/10.1021/acsami. $7 \mathrm{~b} 14626$

13. Z. Wang, B. Jiao, Y. Qing, H. Nan, L. Huang et al., Flexible and transparent ferroferric oxide-modified silver nanowire film for efficient electromagnetic interference shielding. ACS Appl. Mater. Interfaces 12(2), 2826-2834 (2020). https://doi.org/10. 1021/acsami.9b17513

14. L. Liu, W. Chen, H. Zhang, Q. Wang, F. Guan et al., Flexible and multifunctional silk textiles with biomimetic leaf-like MXene/silver nanowire nanostructures for electromagnetic interference shielding, humidity monitoring, and self-derived hydrophobicity. Adv. Funct. Mater. 29(44), 1905197 (2019). https://doi.org/10.1002/adfm.201905197

15. M. Miller, J. O'Kane, A. Niec, R. Carmichael, T. Carmichael, Silver nanowire/optical adhesive coatings as transparent electrodes for flexible electronics. ACS Appl. Mater. Interfaces 5(20), 10165-10172 (2013). https://doi.org/10.1021/am402 $847 \mathrm{y}$

16. W. Chen, L. Liu, H. Zhang, Z. Yu, Flexible, transparent, and conductive $\mathrm{Ti}_{3} \mathrm{C}_{2} \mathrm{~T}_{\mathrm{x}}$ MXene-silver nanowire films with smart acoustic sensitivity for high-performance electromagnetic interference shielding. ACS Nano 14(12), 16643-16653 (2020). https://doi.org/10.1021/acsnano.0c01635 
17. J. Liang, L. Li, K. Tong, Z. Ren, W. Hu et al., Silver nanowire percolation network soldered with graphene oxide at room temperature and its application for fully stretchable polymer light emitting diodes. ACS Nano 8(2), 1590-1600 (2014). https://doi.org/10.1021/nn405887k

18. S. Hong, K. Kim, T. Kim, J. Kim, S. Park et al., Electromagnetic interference shielding effectiveness of monolayer graphene. Nanotechnology 23, 455704 (2012). https://doi.org/10. 1088/0957-4484/23/45/455704

19. T.L. Chen, D.S. Ghosh, V. Mkhitaryan, V. Pruneri, Hybrid transparent conductive film on flexible glass formed by hotpressing graphene on a silver nanowire mesh. ACS Appl. Mater. Interfaces 5(22), 11756-11761 (2013). https://doi.org/ 10.1021/am403440n

20. P. Meenakshi, R. Karthick, M. Selvaraj, S. Ramu, Investigations on reduced graphene oxide film embedded with silver nanowire as a transparent conducting electrode. Sol. Energy Mater. Sol. Cells 128, 264-269 (2014). https://doi.org/10. 1016/j.solmat.2014.05.013

21. H. Lu, J. Sun, H. Zhang, S. Lu, W.C. Choy, Room-temperature solution-processed and metal oxide-free nano-composite for the flexible transparent bottom electrode of perovskite solar cells. Nanoscale 8(11), 5946-5953 (2016). https://doi.org/10. 1039/C6NR00011H

22. B. Zhou, M. Su, D. Yang, G. Han, Y. Feng et al., Flexible MXene/silver nanowire-based transparent conductive film with electromagnetic interference shielding and electro-photothermal performance. ACS Appl. Mater. Interfaces 12(36), 40859-40869 (2020). https://doi.org/10.1021/acsami.0c09020

23. Z. Zhang, G. Wang, W. Gu, Y. Zhao, S. Tang et al., A breathable and flexible fiber cloth based on cellulose/polyaniline cellular membrane for microwave shielding and absorbing applications. J. Colloid Interface Sci. 605, 193-203 (2022). https://doi.org/10.1016/j.jcis.2021.07.085

24. Z. Lou, Q. Wang, U.I. Kara, R.S. Mamtani, X. Zhou et al., Biomass-derived carbon heterostructures enable environmentally adaptive wideband electromagnetic wave absorbers. Nano-Micro Lett. 14, 11 (2021). https://doi.org/10.1007/ s40820-021-00750-Z

25. Y. Song, F. Yin, C. Zhang, W. Guo, L. Han et al., Threedimensional ordered mesoporous carbon spheres modified with ultrafine zinc oxide nanoparticles for enhanced microwave absorption properties. Nano-Micro Lett. 13, 76 (2021). https://doi.org/10.1007/s40820-021-00601-x

26. P. Song, B. Liu, C. Liang, K. Ruan, H. Qiu et al., Lightweight, flexible cellulose-derived carbon aerogel@reduced graphene oxide/PDMS composites with outstanding EMI shielding performances and excellent thermal conductivities. Nano-Micro Lett. 13, 91 (2021). https://doi.org/10.1007/ s40820-021-00624-4

27. J. Li, F. Zhang, H. Lu, W. Guo, X. He et al., Heterogeneous rod-like Ni@C composites toward strong and stable microwave absorption performance. Carbon 181, 358-369 (2021). https://doi.org/10.1016/j.carbon.2021.05.031

28. J. Liu, L. Liu, X. Wu, X. Zhang, T. Li, Environmentally friendly synthesis of graphene-silver composites with surface-enhanced Raman scattering and antibacterial activity via reduction with $\mathrm{L}$-ascorbic acid/water vapor. New J. Chem. 39, 5272-5281 (2015). https://doi.org/10.1039/c5nj00414d

29. J. Ma, W. Li, Y. Fan, J. Yang, Q. Yang et al., Ultrathin and light-weight graphene aerogel with precisely tunable density for highly efficient microwave absorbing. ACS Appl. Mater. Interfaces 11(49), 46386-46396 (2019). https://doi.org/10. 1021/acsami.9b17849

30. R. Guo, Q. Zheng, L. Wang, Y. Fan, W. Jiang, Porous N-doped $\mathrm{Ni} @ \mathrm{SiO}_{2}$ /graphene network: three-dimensional hierarchical architecture for strong and broad electromagnetic wave absorption. J. Mater. Sci. Technol. 106, 108-117 (2022). https://doi.org/10.1016/j.jmst.2021.07.046

31. Y. Song, F. Yin, C. Zhang, H. Yu, W. Jing et al., Inverse-opalbased carbon composite monoliths for microwave absorption applications. Carbon 166, 328-338 (2020). https://doi.org/10. 1016/j.carbon.2020.05.020

32. T. Hou, Z. Jia, B. Wang, H. Li, X. Liu et al., Metal-organic framework-derived $\mathrm{NiSe}_{2}-\mathrm{CoSe}_{2} @ \mathrm{C} / \mathrm{Ti}_{3} \mathrm{C}_{2} \mathrm{~T}_{\mathrm{x}}$ composites as electromagnetic wave absorbers. Chem. Eng. J. 422, 130079 (2021). https://doi.org/10.1016/j.cej.2021.130079

33. J. Gao, F. Liu, Y. Liu, N. Ma, Z. Wang et al., Environmentfriendly method to produce graphene that employs vitamin C and amino Acid. Chem. Mater. 22(7), 2213-2218 (2010). https://doi.org/10.1021/cm902635j

34. G. Wang, L. Hao, X. Zhang, S. Tan, M. Zhou et al., Flexible and transparent silver nanowires/biopolymer film for highefficient electromagnetic interference shielding. J. Colloid Interface Sci. 607, 89-99 (2021). https://doi.org/10.1016/j. jcis.2021.08.190

35. M. Jing, C. Han, M. Li, X. Shen, High performance of carbon nanotubes/silver nanowires-PET hybrid flexible transparent conductive films via facile pressing-transfer technique. Nanoscale Res. Lett. 9, 588 (2014). https://doi.org/10.1186/ 1556-276X-9-588

36. J. Goak, T. Kim, D. Kim, K. Chang, C. Lee et al., Stable heating performance of carbon nanotube/silver nanowire transparent heaters. Appl. Surf. Sci. 510, 145445 (2020). https://doi. org/10.1016/j.apsusc.2020.145445

37. S. Lee, J. Kim, J. Park, Y. Porte, J. Kim et al., SWCNT-Ag nanowire composite for transparent stretchable film heater with enhanced electrical stability. J. Mater. Sci. 53, 1228412294 (2018). https://doi.org/10.1007/s10853-018-2526-7

38. Y. Zhang, S. Bai, T. Chen, H. Yang, X. Guo, Facile preparation of flexible and highly stable graphene oxide-silver nanowire hybrid transparent conductive electrode. Mater. Res. Express 7, 016413 (2020). https://doi.org/10.1088/2053-1591/ab6262

39. J. Miao, H. Liu, W. Li, X. Zhang, Mussel-inspired polydopamine-functionalized graphene as a conductive adhesion promoter and protective layer for silver nanowire transparent electrodes. Langmuir 32(21), 5365-5372 (2016). https://doi. org/10.1021/acs.langmuir.6b00796

40. J. Li, S. Qi, J. Liang, L. Li, Y. Xiong et al., Synthesizing a healable stretchable transparent conductor. ACS Appl. Mater. Interfaces 7(25), 14140-14149 (2015). https://doi.org/10. 1021/acsami.5b03482 
41. S. Sung, T.W. Kim, Flexible nonvolatile memory devices based on Au/PMMA nanocomposites deposited on PEDOT: PSS/Ag nanowire hybrid electrodes. Appl. Surf. Sci. 411, 67-72 (2017). https://doi.org/10.1016/j.apsusc.2017.03.112

42. T. Wang, W.W. Kong, W.C. Yu, J.F. Gao, K. Dai et al., A healable and mechanically enhanced composite with segregated conductive network structure for high-efficient electromagnetic interference shielding. Nano-Micro Lett. 13, 162 (2021). https://doi.org/10.1007/s40820-021-00693-5

43. G. Wang, S.J.H. Ong, Y. Zhao, Z.J. Xu, G. Ji, Integrated multifunctional macrostructures for electromagnetic wave absorption and shielding. J. Mater. Chem. A 8(46), 24368-24387 (2020). https://doi.org/10.1039/D0TA08515D

44. J. Wang, Z. Jia, X. Liu, J. Dou, B. Xu et al., Construction of 1D heterostructure NiCo@C/ZnO nanorod with enhanced microwave absorption. Nano-Micro Lett. 13, 175 (2021). https://doi. org/10.1007/s40820-021-00704-5

45. X. Liang, G. Wang, W. Gu, G. Ji, Prussian blue analogue derived carbon-based composites toward lightweight microwave absorption. Carbon 177, 97-106 (2021). https://doi.org/ 10.1016/j.carbon.2021.02.063

46. Y. Choi, S. Gong, D. Johnson, S. Golledge, G. Yeom et al., Characteristics of the electromagnetic interference shielding effectiveness of Al-doped $\mathrm{ZnO}$ thin films deposited by atomic layer deposition. Appl. Surf. Sci. 269, 92-97 (2013). https:// doi.org/10.1016/j.apsusc.2012.09.159

47. T. Yamada, T. Morizane, T. Arimitsu, A. Miyake, H. Makino et al., Application of low resistivity Ga-doped $\mathrm{ZnO}$ films to transparent electromagnetic interference shielding material. Thin Solid Films 517(3), 1027-1031 (2008). https://doi.org/ 10.1016/j.tsf.2008.06.047

48. Z. Lu, L. Ma, J. Tan, H. Wang, X. Ding, Transparent multilayer graphene/polyethylene terephthalate structures with excellent microwave absorption and electromagnetic interference shielding performance. Nanoscale 8(37), 16684-16693 (2016). https://doi.org/10.1039/C6NR02619B
49. S. Kim, J. Oh, M. Kim, W. Jang, M. Wang et al., Electromagnetic interference (EMI) transparent shielding of reduced graphene oxide (RGO) interleaved structure fabricated by electrophoretic deposition. ACS Appl. Mater. Interfaces 6(20), 17647-17653 (2014). https://doi.org/10.1021/am503893v

50. T. Yun, H. Kim, A. Iqbal, Y. Cho, G. Lee et al., Electromagnetic shielding of monolayer MXene assemblies. Adv. Mater. 32(9), 1906769 (2020). https://doi.org/10.1002/adma.20190 6769

51. N. Zhang, Z. Wang, R. Song, Q. Wang, H. Chen et al., Flexible and transparent graphene/silver-nanowires composite film for high electromagnetic interference shielding effectiveness. Sci. Bull. 64(8), 540-546 (2019). https://doi.org/10.1016/j. scib.2019.03.028

52. F. Qin, Z. Yan, J. Fan, J. Cai, X. Zhu et al., Highly uniform and stable transparent electromagnetic interference shielding film based on silver nanowire-PEDOT: PSS composite for high power microwave shielding. Macromol. Mater. Eng. 306(2), 2000607 (2020). https://doi.org/10.1002/mame.202000607

53. K.S. Moon, H. Dong, R. Maric, S. Pothukuchi, A. Hunt et al., Thermal behavior of silver nanoparticles for low-temperature interconnect applications. J. Electron. Mater. 34, 168-175 (2005). https://doi.org/10.1007/s11664-005-0229-8

54. M. Singh, T.R. Rana, S. Kim, K. Kim, J.H. Yun et al., Silver nanowires binding with sputtered $\mathrm{ZnO}$ to fabricate highly conductive and thermally stable transparent electrode for solar cell applications. ACS Appl. Mater. Interfaces 8(20), 1276412771 (2016). https://doi.org/10.1021/acsami.6b01506

55. D. Chen, F. Zhao, K. Tong, G. Saldanha, C. Liu et al., Mitigation of electrical failure of silver nanowires under current flow and the application for long lifetime organic light-emitting diodes. Adv. Electron. Mater. 2(8), 1600167 (2016). https:// doi.org/10.1002/aelm.201600167 